\title{
Shaping a Public Secondary School Culture of Volunteer Commitment During the Economic Crisis in Greece
}

\author{
Styliani Lalagka ${ }^{1}$, Areti Valasidou ${ }^{2}$ \\ ${ }^{1}$ Department of Education, University of Derby, Derby, UK \\ ${ }^{2}$ Department of International European Studies, University of Macedonia, Thessaloniki, Greece
}

Email address:

liana.lalaga@gmail.com (S. Lalagka), valasid@uom.gr (A. Valasidou)

\section{To cite this article:}

Styliani Lalagka, Areti Valasidou. Shaping a Public Secondary School Culture of Volunteer Commitment During the Economic Crisis in Greece. International Journal of Secondary Education. Vol. 3, No. 6, 2015, pp. 55-60. doi: 10.11648/j.ijsedu.20150306.11

\begin{abstract}
Times of economic crisis bring changes. Low funding and sequential problems provide new challenges for school community in order to move forward. This paper demonstrates a completely volunteer program for a Greek, public secondary school, involving the whole school community, school staff, students, parents and citizens, and aiming to shape the school culture into volunteer commitment during hard times. Our research is based on secondary data that were retrieved by up to date sources that aimed to discuss the volunteerism and its impact on modern educational leadership. We discuss the case study of Western Australian schools that used a volunteerism program and we discuss how this can be implemented at Greek schools. Working throughout international literature we found a complete volunteer program for organizations and we adapted it for Greek public secondary school. In order this project to be achievable we suggest a transformational leader who is charismatic and visionary to be the head teacher of the school. On reimaging schooling, our assumption was that if a public school could shape a volunteer commitment by all school members then the consequences of economic crisis will be more easily hand able.
\end{abstract}

Keywords: Transformational Leadership, Volunteerism, Economic Crisis, Secondary School, Greek School

\section{Introduction}

Times have changed, and the old, stricken, and commanded way of management is no longer effective and efficient, in a world which changes rapidly, creating an uncertain atmosphere (Horney, 2007 as cited in Rothwell, Prescott and Taylor).

According to Horney (cited in Rothwell et al., 2007) "leadership is a special quality that enables teams and organizations to achieve extraordinary success", and Kotter (1990) argues that "leadership is about generating constructive change"

Following the advance of psychology, scientists studied the attitudes of variety of leaders' attitudes through years, and classified them into theories and styles, based on their specific traits (autocratic, behavioral, ethical, transactional, transformational etc).

\section{Transformational Leadership in Managing the New Social-Economic Conditions}

A transformational leader who was often related to charismatic and visionary leaders, is a leader who can "change the culture of organization and of its member, by possessing new attitudes, values and visions" (Western, 2008, p.109).

Psychologist Bernard Bass (as cited in Lopez, 2009) worked on transformational leadership's concept further outlining its components, as the four "I".

\subsection{Idealized Influence}

Transformational leaders lead by their example, serving positive models for their followers, emphasizing the collegiate mission of the team or organization and demonstrating high ethical standards. Consequently, followers believe in their leader's extraordinary capabilities, in his/her ability to direct and they have respect of the leader.

\subsection{Inspirational Motivation}

Followers are been inspired and motivated by their leader who is optimist, enthusiastic and able to articulate attractive future outcomes. Both the idealized influence and the inspirational motivation compose the transformational leader's charisma. 


\subsection{Intellectual Stimulation}

Transformational leaders question assumptions, reframe problems and challenge their followers to try new approaches. As a result, leader encourage them in an effort to stimulate forward thinking and novel creativity.

\subsection{Individualized Consideration}

The transformational leaders know that there are differences in their followers and they pay particular attention each one's need and concern, and through mentoring and coaching they focus on their followers' personalized development and growth.

Later on, Bass included the moral component in his transformational leader's conceptualization, as this style of leader can sense people emotions and can be in others shoes.

\section{The Consequences of Economic Crisis in Public Secondary Schools}

It is world-wide known that when a state faces an economic crisis, one of the main priorities, in order to handle the crisis, is to reduce the funds. The Greek Educational System is not an exception, when Greek government proceeded to make severe cuts of funding's, and decreased teachers' salary up to almost $30 \%$.

Consequently, school leaders face the following problems (ETUCE, 2012):

- The school does not have the ability to provide all the materials and technological appliances which are needed for the students and the staff, or even the ability to keep the building in good condition (caring about its tidiness and repairing every possible damage)

- School teachers trying to reduce the cost of their transportation to work, seek to be closer to their home, or they move to another places, and so the composition of teaching staff changes almost every year.

- The merges of school and also the increasing of taxes forces a lot of parents whose children previously attended private schools, to send them to public schools, so the number of students rises.

- Decreasing of recruiting teachers causes the lack of expertized staff)

- Many of students' parents are unemployed, so their families has to face survival, practical and psychological issues, together with their children.

- Teachers' and students' personal problems.

According to Smith and Riley (2012) a crisis in a school environment is an emergency situation in which the headmaster must act fast and decisively, and they suggest five steps in order to respond to the crisis:

- Acknowledging reality. The successful school's response to the crisis depends on the amount, relevant, qualities and reliable information it has.

- Planning. A plan must be adapted and implemented in order to handle the crisis.

- Decision making. Be decisive give the sense of optimism that "all is under control".

- Showing consideration. Crisis are situations where leader's ethics are on display. Now, the leader will show his/her real concern of others, consolidating strong bonds between leadership and the employees and both will be able to address the crisis.

- Communication. Avoid rumors, confusion, and misinformation, through an open, clear and on time communication.

\section{The Importance of Voluntarism in an Era of Economic Crisis}

According to Connors (2012), voluntarism is the systematic, free-willing service aiming to attain an organization's goals in a changing milieu. In hard financial times new principles, behaviors, and trade activities arise in order to handle the new circumstances (Raymond, 2010; 140).

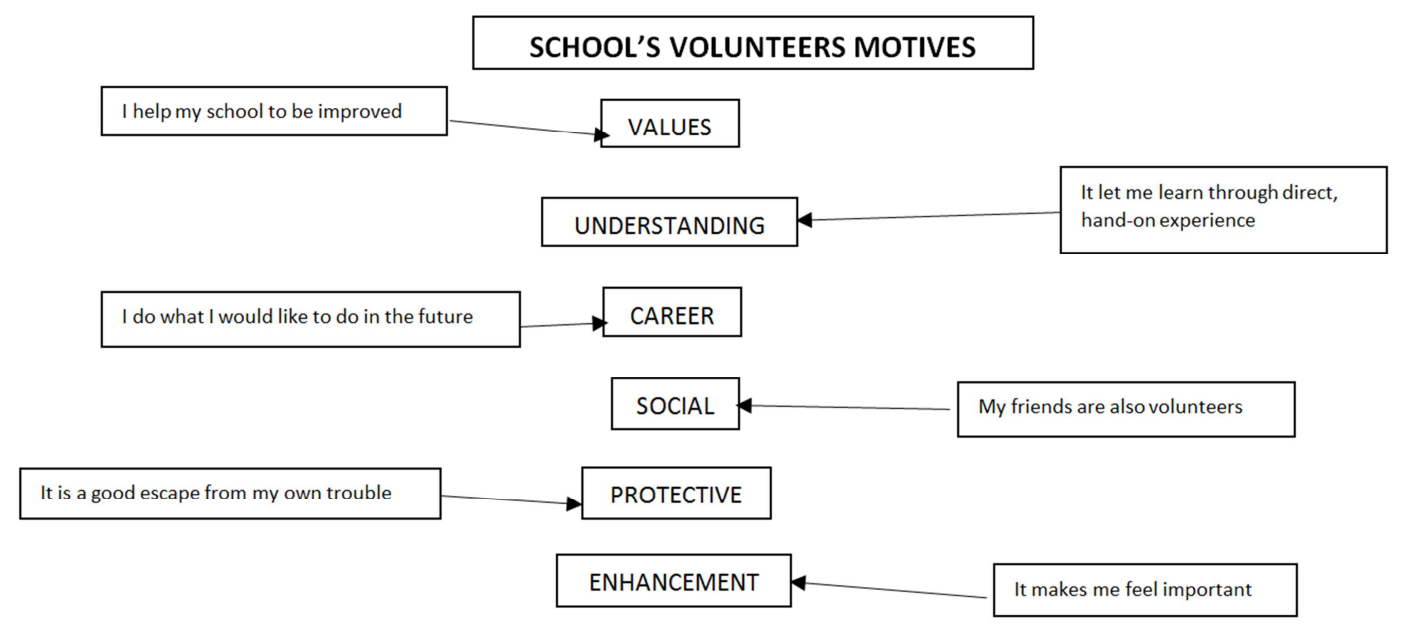

Source: Newton, K., Becker, K. \& Bell, S. (2014) "Learning and development opportunities as a tool for the retention of volunteers: a motivational perspective". School of management, QUT Business School, Queensland University of Technology Human Resource Management Journal, vol. 24 , no 4, pp 514-530.

Figure 1. School's volunteers motives. 
According to Raymond (2010; 140) "the successful organization must embed its community of supporters throughout its operations. During hard times, develop new mechanisms for doing just that. Develop new jobs and new roles for volunteers. Develop entirely new approaches to volunteerism."

Rainman in Connors (2012) refers that hard times offer a unique opportunity for volunteers to contribute in their communities, improving the quality of life and human services. It is clear that the volunteer leadership plays a significant role in translation the motivation, resources, interest, and skills of volunteers into human.

Volunteers, motivated from different reasons, offer their time, skills and services without any economic compensation, without any obligation (Lanzo and Hanisch as cited in Newton, Becker and Bell, 2014; Reuveni and Werner, 2015). Figure 1

As Steadman points out at Connors book (2012) some leadership styles are able to interact with volunteers. Here is, where transformation leadership style takes place. Through volunteer management program, a transformational leader puts theory into practice by discussing effectively approaches, suggesting strategies and implication for critical thinking and decision making, personalizing actions, sensing people's emotions and leading with his/her example. In the same vein, he/she can shape the school culture into voluntarism. However, policy must be the most urgent consideration of the head teacher, as it communicates values and visions, guides actions and decisions, sets limits and defines responsibilities with in a school environment (Graff, as cited in Connors, 2012). The positive outcomes of a good policy development are:
- The effectiveness of volunteers' involvement

- The provision of a quality program

- Excellent provided services

- Satisfied volunteers

Obviously, policy is an important management tool but it also improves the power of volunteer involvement and the direction of volunteer program by communicating beliefs, and values, articulate regulations, identifying expectations and standards, and setting boundaries. All together support each volunteer while improve the productivity, the work place safety and everyone's satisfaction (Graff, as cited in Connors, 2012)

\section{School Volunteer Program}

Firstly, school leader must discuss with all the member of school community (one after another teachers, students, parents, members of municipality) the difficulties that school faces during the economic crisis and introduce and define the idea of volunteer management. Through systematic and logical actions of working through and with volunteers, they can attain school's objectives in a changing environment (Saffit and Schmiesing as cited in Connors, 2012). By giving answer to the based question "Why are we doing all this?" all members should be involved in planning the school volunteer program ensuring its implementation and its effective and efficient operation. In order to prepare the school community, avoid a possible pitfall or a generation of negative results, leadership must underline everyone's responsibilities and give the correct direction for the volunteer program. (Brundney as cited in Connors, 2012).

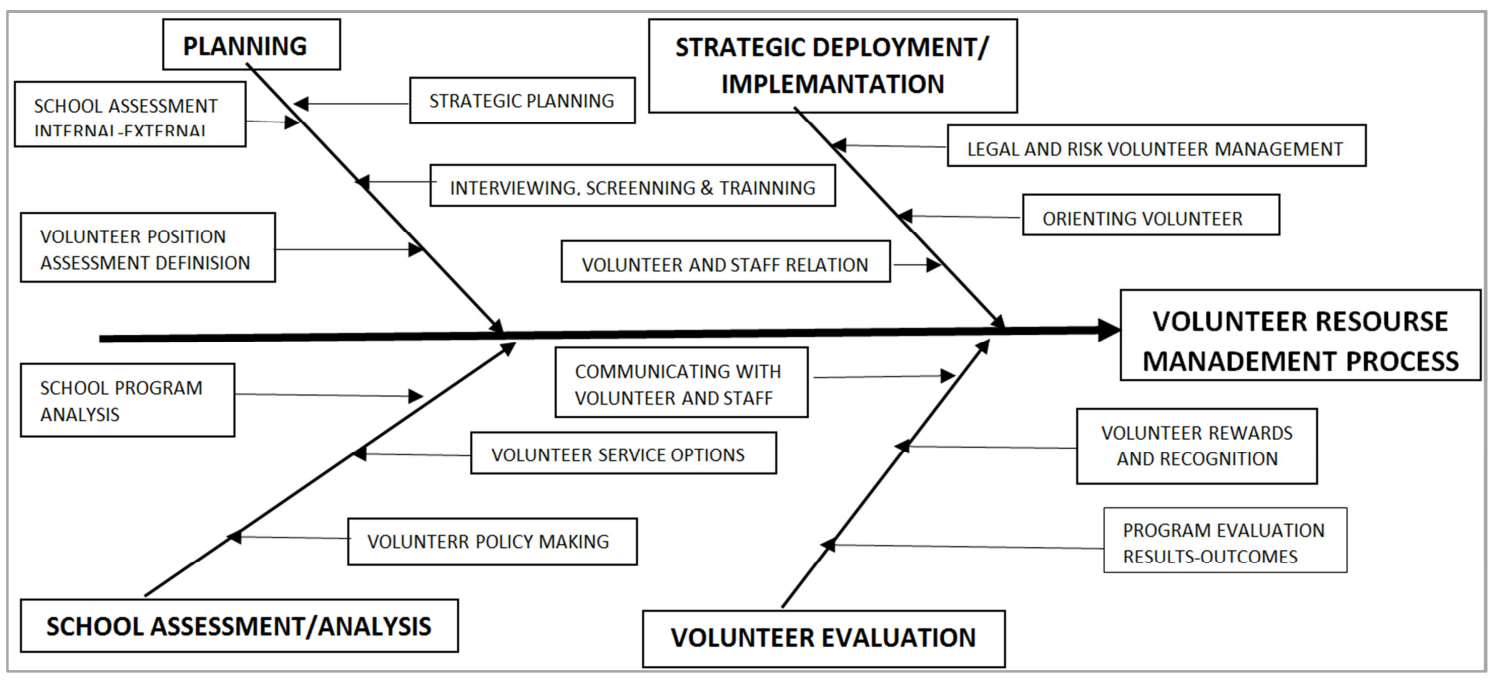

Source: our own study

Figure 2 Fishbone for school volunteer program.

School leader's plan moves among four stages (Connors, 2012):

- School assessment/analysis

- Planning

- Strategic deployment/implementation and
- Results/Evaluation

\subsection{School Assessment and Analysis}

The procedure of volunteer involvement begins with the school assessment and analysis which give forethought and 
enough consideration to how important is a volunteer program for the school (school program analysis), how volunteers are suitable for this program (service options) and their contribution to the school mission and further, how the volunteer engagement will be alive through years, thus creating a voluntarism school culture (volunteers policy making) (Rehnborg et Moore as cited in Connors, 2012).

\subsection{Planning}

According to Yallen and Wentworth (as cited in Connors, 2012) planning is the second vital area, after assessment and analysis, in a volunteer program management and leadership, and aims to the school's goals achievement. Volunteers strategic aims to the school's goals achievement, including the knowledge, abilities, and skills, when there is a part time volunteers or full time volunteers and other characteristics which are necessary, in order to define the newly position successfully. School assessment internal (teachers and students) and external (parents and citizens) is crucial because volunteers will be arise from these two parts by interviewing, screening, training and placement individuals or in groups in specific positions. A transformational leader is able to see their needs, skills and personal development and growth, and motivate them in a particular way (e.g. School needs boxes of paint in order classrooms to be painted by teachers and students during weekend. Two or more students, in their free time, offer their services to the paint store and instead of money they gain the boxes).

\subsection{Strategic Deployment and Implementation}

The strategic deployment and implementation start from the legal and risk management. As Graff points out in Connors book (2012), all volunteer participation generates risks. However, the consequences may be incalculable if the leader do not consider any possible risk. A well-organized risk management aims to avoid risks or to find solutions at any aroused danger by asking the right questions, in the right way, throughout all stages of school volunteer program and indeed throughout the school. School leader ought to make all the necessary procedures in order to protect volunteers from every danger which about to happen physical or legal. (e.g. Parents' permission is very important because a student may be sensitive to colors' smell.). Volunteers' orientation is essential, too. According to Gotlied (as cited in Connors, 2012) volunteers want a range of options, supervision, good handling, control, clear job details, recognition, training and acceptation. They do what they do because they feel valuable. Further, volunteers want supervision over the positions they cover for the school and, where possible to match their volunteer commitment with the personal life and their profession. A significant role for head teacher is to ensure that both the volunteer and the school have a successful experience (Gotlieb as cited in Connors, 2012). As Power refer to Connors (2012) "the people do the work they do for reasons are related to the cause, and that often includes adverse experiences". One very important issue is the relationship between volunteers and staff (e.g unemployment staff who support weak students, with paid staff) which can be characterized as the school's "dirty secret" (Macduff, as cited in Connors, 2012). The relation between them is both complex and critical, and it depicts the determination of volunteer engagement, the total success of the school's volunteer program, and above all of the school's ability to attain its mission successfully. It is no secret, that a team work throughout the organizations delivers more effective and more efficient services to its members. Identifying any symptoms of bad volunteer-staff relationships can be significant to the survival of the school's volunteer program. Therefore, the school leader must make a great effort to build an excellent volunteer-staff team, "which pulling together they can provide the collective energy and direction to propel the school vehicle toward its goal of mission accomplishment- or it can pull the vehicle into pieces" (Macduff, as cited in Connors, 2012). The importance of volunteer recognition answers the question "how do volunteers feel?" According to Connors (2012),"everyone needs to feel needed. Feeling needed bolsters self-esteem, sense of self-work, and the feeling that one has a place in life". Volunteer feel needed when others can lay on them. Volunteers feel visible when they are able to serve others' needs, desires and expectations. The feedback let the head teacher know how successful it is in making volunteers feel appreciated and valued. In evaluation, the positive experience for both the volunteers and the school is the crucial first step, and all members ought to realize the benefits that the satisfied volunteers bring with their participation. A well-organized procedure will empower volunteers' enthusiasm for their obligation and they feel that "they have made the right decision" (Edwards, as cited in Connors, 2012).

\subsection{Results and Evaluation}

Furthermore, as Bortee refers (as cited in Connors, 2012) the evaluation of a school volunteer program can be through real communication between volunteers and school staff. Of course, a transformational leader cannot "underestimate the importance of keeping an open line of communication" with all members which are been involved in school program. The communication builds strong relation between the school and its volunteers and staff, and new paths and trends being used in the educational field. When communication is clear, frequent, transparent and meaningful, it can be an important component in a positive relation between all members (volunteers, staff) and leadership, and it is a channel where positive and negative points of school volunteer program can be depicted. Informing, convincing and stimulating staff and volunteers toward school objectives can be challenging. However, "change is more easily achieved when the school leadership maintains a positive relationship with these audiences through effective communication" (Bortree, as cited in Connors, 2012). School volunteer program evaluation (measurement) is among the most important ingredients require for an effectiveness program management and it documents the impact and worth of the program on all members, especially the students, for 
whom it is designed as well as the larger society in which the school operates. School volunteers program aims to create positive results and impacts and in the life of all members (Safrit, as cited in Connors, 2012).

\section{Examples of the School Volunteer Program}

The school volunteer program can include some of the following examples

- Extra lessons by the school teachers or unemployed parents who have studied the specific science, in order to improve the learning outcomes of students (Robinson and Rennie, 2014).

- A team of teachers and students who love nature can take care of the plants, the trees, and the loan of the school.

- Parents who are nurses or doctors can give their services to pupils who face economic problems and offer free first aids seminars to all school members.

- Students in secondary school usually know more about computers in comparison with adults. So, they can teach parents how to use a computer always of course under their teacher's supervision.

- Groups of teachers and students can fix damages or they can paint classrooms.

- Extra sports activities can be held in the afternoon from teachers of physical education or parents who used to be an athlete (Oncescu and Giles, 2013).

\section{Case of a School Volunteer Program}

In Western Australia, a school volunteer program took place in order to identified community needs. It concentrated on the possibility of citizens assisting students were experiencing difficulties in the upper primary and lower secondary school. There was an urgent need for young people to be guided with basic academic, social, and life skills. In Western Australia and throughout Australia schools found that at least 20 percent of their pupils were being categorized as "pupils at educational risk". This may be due to many causes, including low numeracy and literacy skills, low self-esteem, behavioral problems, the lack of home support, non- English speaking, health problems, learning disabilities, inadequate social skills, or they may even be gifted children. Whatever the reason, research shows that pupil's categorization of being "at risk" can transform significantly, rely on the support or lack of support they receive at home and at school. This is where the marvelous resource of trained volunteers from the society, as mentors in the school, can make such a difference (Tracey et al, 2014).

As has been reported by Gray (2008), from 1996 since 2008, where the article was written, a school volunteer program was implemented in 250 public schools, involving 1,800 volunteers (16-93 years old) and 2,500 students (5-12 years old), aiming to support positive stance to learning, improve life's skills, promote positive relations between generations, foster the principals of voluntarism and prompt others volunteers to get involved. All volunteers, having only life experience, patience and love for people, attended 3 hour training seminars, and they worked 1 hour per week under the supervision and guidelines of the school they mentored. This program made a great difference in the life of thousands of children, students, and adults, developing positive self-esteem, altruistic feelings, and sculpting valuable members in their community (Tracey et al, 2014).

\section{Conclusions}

As our economy has slowed, volunteers have become even more vital to the health and quality of people's life. (Rainman, as cited in Connors2012). As Smith underlines in Connors (2012) a successful school volunteer culture is based mostly on its compelling visions, a charismatic head teacher, and whether the specific volunteers' position depict a perfect match of their skill and services they offer. Next year, while new coming members are going to join the existing program, the school culture is the magic hand which is going to attract them to commit to the school's objectives. Otherwise, if the school culture has a low impact on them, they will not be obligated, and they will be a thorn in the whole project. Establishing a school volunteer culture is not easy, needs a lot of work and commitment from all school members, beginning from the head teacher, and it is essential in order the Greek, public, secondary schools move forward and handle the economic crisis.

Obviously, transformational school leadership is the key factor because through its traits it can shape the school culture into volunteerism by discussing effectively approaches, suggesting strategies and implication for critical thinking and decision making, personalizing actions and sensing people's emotions. A transformational leader can facilitate the implementation of a well-organized school volunteer program in four stages: school assessment and analysis, planning, strategic deployment and implementation and school volunteer program evaluation.

In Greece, the head teacher changed every four years in the past but, nowadays, according to the new law the school leader is elected by the teaching staff, every two years. Consequently, head teachers' choice must be based on specific criteria in order the school goals to be achievable. However, what will happen if the school leader retires or leaves the school? Will, then, the rest of the school's members which compositions changes almost every year, be able to continue the volunteer program successfully due to economic conditions which needs too many years in order to stand on its feet?

The world is changing, the school is changing, the role of teachers is changing, teachers and students are changing, and volunteers are changing as a reflection of a changing social environment (Smith, as cited in Connors, 2012). Connors supplements that "The winds of change blow us this way and that. Without a vision and a plan, we have a little chance of affecting whatever outcome lies ahead". In the same vein, 
Hobbs (as cited in Connors, 2012) parallels that "Volunteers are the lifeblood of a volunteer-based school. While the school mission, vision, and values are the backbone, the teaching staff, the skeleton system, the students, the organs of the body, and the community, the skin, it is the lifeblood-sharing efforts of the volunteers that keep the body nourished and vibrant during hard times". It is teachers and adults role to give values, hope and visions to the new generations.

\section{References}

[1] Astin, A.W., Sax, L. J. \& Avalos, J. (1999) "Long-term effects of volunteerism during the undergraduate year", Review of Higher Education, vol. 22, issue 2, pp 187-202. John Hopkins University Press.

[2] Bonnici, C.A. \& Cooper, B.S., (2001) "Creating a Successful Leadership Style: Principles of Personal Strategic Planning", Maryland: Rowman \& Little Field Publishers.

[3] Coleman, M. \& Glover, D., (2010) "Educational Leadership and Management: Developing Insights and Skills", Berkshire: Open University Press.

[4] Connors, T. (2012) "The volunteer management Handbook: Leadership Strategies for Success" $2^{\text {nd }}$ ed, Hoboken: John Wiley \& Sons.

[5] Davies, B. \& Davies, J., (2011) "Talent Management in Education", London: Sage.

[6] Eisner, D., Grim, R., Maynard, S. \& Washburn, s. (2009) “The new Volunteer Workforce", Stanford Graduate School of Business. Social Innovation Review-Winter 2009, pp. 32-37.

[7] European Trade Union Committee of Education (ETUCE), (2014) "The crisis and the drown-outs effects on education since 2008: the views of the teachers in Europe", Education International. Belgium, 2014 Available at: http://etuce.homestead.com/

Statements/2014/20140127_ANNEX_TO_ETUCE_PLEDGE _Crisis_comparison_2008-2013.pdf.

[8] Grout, J. \& Fisher, L., (2007) "What do Leaders really do: getting under the skin of what makes a Great", Chicheter: Capstone Publishing.

[9] Gunter, H. (2012) "Leadership and the reform of Education", Bristol: The Policy Press.
[10] Lopez, S. (2009) "The Encyclopedia of Positive Psychology", Volume I/A-M, Oxford: Wiley-Black well.

[11] McAdam, D. \& Brandt, C., (2009) "Assessing the Effects of Voluntary Youth Service: The case of Teach in America", Social Forces. Dec. 2009, Vol. 88. Issue 2, p. 945-969. 25p Database: Business Source Premier. DOI: 10.1353/sof.0.0279

[12] Newton, K., Becker, K. \& Bell, S., (2014) "Learning and development opportunities as a tool for the retention of volunteers: a motivational perspective", School of management, QUT Business School, Queensland University of Technology Human Resource Management Journal, vol. 24, no 4, pp 514-530. Available at: onlinelibrary.wiley.com.ezproxy.derby.ac.uk/doi/10.1111/1748 $-8583.12040 /$ epdt eprints.qut.edu.au/711457.

[13] Oncescu, J. \& Giles, A. (2013) “A rural school's closure: Impacts on volunteers' gender roles", Rural Society, vol. 23, issue 1, pp. 2-19, Taylor \& Francis.

[14] Raymond, S., (2010) "Nonprofit Finance for Hard Times: Leadership Strategies when Economic Falter", Hoboken: John Wiley \& Sons.

[15] Reuveni, Y. \& Werner, P. (2015) "Factors associated with teenagers' willingness to volunteer with elderly persons: Application of the Theory of Planned Behavior (TPB)", Educational Gerontology, vol. 41, issue 9, pp. 623-634, University of Haifa, Haifa.

[16] Robinson, D. \& Rennie, S, (2014) "Volunteer teachers: Testing the professionalization agenda in the lifelong learning sector" Journal of Further \& Higher Education, vol.38, issue 4, pp.501-522, British Education Index.

[17] Rothwell, W., Prescott, R. \& Taylor, M., (2008) "Human Resource Transformation: Demonstrating Strategic Leadership in the face of Future Trends", Davie-Black Publications.

[18] Tracey, D, Horney, S. Seaton, M., Craven, R. \& Yeung, A., (2014) "Volunteers Supporting Children with Reading Difficulties in Schools: Motives and Rewards" School Community Journal, Spring 2014, vol. 24, issue 1, pp. 49-68.

[19] Wallach, H., "Voluntary Work Experience for College: Students who Volunteer and How does the Experience Influence the Self-Concept. Mental Health and Strategies", [e-book]. Hauppauge N.Y., U.S.: Nova Sciences Publisher, 2006, pp. 59-78.

[20] Western, S. (2008) "Leadership: A Critical Text", London: Sage. 